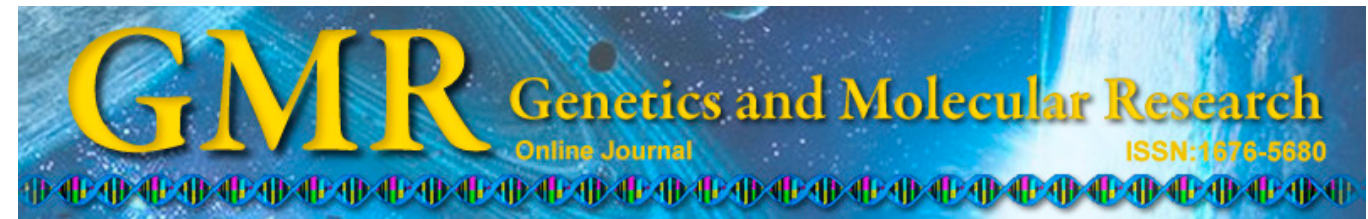

\title{
Novel polymorphisms of the $P R K A G 2$ gene and their association with body measurement and meat quality traits in Qinchuan cattle
}

\author{
C.Z. Fu ${ }^{1,2}$, W.Q. Tian $^{3,4}$, Y.K. Li ${ }^{1}$, S.J. Wei ${ }^{1}$, G. Cheng ${ }^{1,3}$, H.B. Wang ${ }^{1,3}$ and \\ L.S. Zan ${ }^{1,3}$ \\ ${ }^{1}$ College of Animal Science and Technology, Northwest A\&F University, \\ Yangling, Shaanxi, China \\ ${ }^{2}$ College of Life Science and Technology, Dalian University, Dalian, \\ Liaoning, China \\ ${ }^{3}$ National Beef Cattle Improvement Center of Northwest A\&F University, \\ Yangling, Shaanxi, China \\ ${ }^{4}$ Yangling Vocational \& Technical College, Yangling, Shaanxi, China \\ Corresponding author: L.S. Zan \\ E-mail: zanlinsen@163.com
}

Genet. Mol. Res. 14 (2): 3669-3679 (2015)

Received May 22, 2014

Accepted August 22, 2014

Published April 17, 2015

DOI http://dx.doi.org/10.4238/2015.April.17.16

\begin{abstract}
Body measurement and meat quality traits play important roles in the evaluation of productivity and economy in cattle, which are influenced by genes and environmental factors. PRKAG2, which encodes the $\gamma 2$ regulatory subunit of AMPK, is associated with key metabolic pathways in muscle. We detected bovine PRKAG2 gene polymorphisms and analyzed their associations with body measurement and meat quality traits of cattle. DNA samples were taken from 578 Qinchuan cattle aged 18-24 months. DNA sequencing, polymerase chain reaction-restriction fragment length polymorphism, and timeof-flight mass spectrometry were used to detect PRKAG2 single nucleotide polymorphisms (SNPs). Sequence analysis revealed three SNPs in exon 3 (g.95925G $>$ A, g.95973G $>$ C, and g.95992A $>$ G) and
\end{abstract}


one g.96058T $>$ C mutation in intron 3. g.95973G $>$ C, g. $95992 A>G$, and g.96058T $>$ C each showed 3 genotypes: GG, GC, and CC; AA, AG, and GG; and TT, TC, and CC, respectively. In contrast, g.95925G $>$ A only showed 2 genotypes, GG and GA. Analysis showed that g.95925G $>$ A had no effects on body measurement and meat quality traits, whereas the other 3 polymorphisms were significantly associated with some of the body measurement and meat quality traits in the Qinchuan cattle population. It is inferred that the $P R K A G 2$ gene can be used for markerassisted selection to improve the body measurement and meat quality traits in the Qinchuan cattle population.

Key words: Body measurement traits; Meat quality traits; PRKAG2; Qinchuan cattle; Single nucleotide polymorphism

\section{INTRODUCTION}

Some genetic markers are associated with important economical traits of livestock species; via marker-assisted selection, the identification of the marker has the potential to alter the genetic improvement rate (Nkrumah et al., 2003). The genes associated with adult height have been identified and provided important insights to analyze the genetics of polygenic quantitative traits (Weedon et al., 2007).

AMP-activated protein kinase (AMPK) is a metabolic regulator that is responsible for adjusting the energy supply to match demands (Oliveira et al., 2012). AMPK, consisting of an $\alpha$ catalytic subunit and $\beta$ and $\gamma$ regulatory subunits, is a heterotrimer complex found in all eukaryotic cells. During hypoxia and ischemia, it plays an essential role in activating glucose transport (Ofir et al., 2008). Dominant mutations in the $\gamma 2$ regulatory subunit of AMPK, which is encoded by the gene PRKAG2, could cause cardiac hypertrophy and increase the risk of sudden cardiac death. Mutations in PRKAG2 produce a distinctive cardiac histopathology characterized by enlarged myocytes with vacuoles containing glycogen derivatives (Blair et al., 2001; Gollob et al., 2001; Arad et al., 2002). In transgenic mouse models, it has been confirmed that PRKAG2 mutations were associated with glycogen cardiomyopathy (Arad et al., 2003; Sidhu et al., 2005; Davies et al., 2006). Human mutations in PRKAG2 could cause unique cardiomyopathy characterized by ventricular pre-excitation, myocardial hypertrophy, and progressive conduction system disease (Arad et al., 2002). In transgenic mice overexpressing the human PRKAG2 mutation in their hearts, glycogen storage and other features of this disease were completely recapitulated (Arad et al., 2003). In contrast, transgenic mice overexpressing the wild-type $P R K A G 2$ gene showed a milder increase in glycogen, which could cause mild hypertrophy without cardiomyopathy (Ofir et al., 2008).

So far, no polymorphisms of the PRKAG2 gene in Qinchuan cattle have been reported. Thus, discovering and discussing the genetic variations in the PRKAG2 gene in Qinchuan cattle is preliminary and interesting work. The genetic variations in the PRKAG2 gene were first identified by DNA sequencing and polymerase chain reaction-restriction fragment length polymorphism (PCR-RFLP) technology, which will possibly contribute to constructing genetic markers to analyze the association between the genotype and the body measurement and meat quality traits. The information about the PRKAG2 gene obtained in this study will provide some useful assistance for further research. 


\section{MATERIAL AND METHODS}

\section{DNA samples and data collection}

A total of 578 adult animals aged 18-24 months were randomly selected to be unrelated for at least 3 generations from 1 Qinchuan cattle-breeding population and used to analyze the PRKAG2 allelic frequencies. The body measurement traits (BMTs), including body length (BL), withers height (WH), hip height (HH), rump length (RL), hip width (HW), chest depth (CD), heart girth (HG), and pin bone width (PBW), were measured as previously described (Gilbert et al., 1993). Ultrasound measurements were available for meat quality traits (MQTs) (Brethour, 1994; Hamlin et al., 1995), including backfat thickness (BT), loin muscle area (LMA), and intramuscular fat content (IFC). A single person was assigned to measure 1 of the 11 traits in all animals to minimize systematic error. DNA samples were extracted from the blood samples derived from the jugular vein of the 578 Qinchuan cattle using a standard phenol-chloroform protocol (Müllenbach et al., 1989).

\section{PCR amplification and DNA sequencing}

According to the sequence of the bovine PRKAG2 gene (GenBank accession No. NC_007302.5), 1 pair of primer sequences (F: 5'-TCCGAGGGACCTCACCTGT-3'; R: 5'-CACCCACCTGGAACAAAAGC-3') were designed by the Primer Premier 5.0 software to amplify PCR products including exon 3 and partial intron 3. PCR amplifications were performed in a $20-\mu \mathrm{L}$ reaction mixture containing $20 \mathrm{ng} \mathrm{DNA}, 10 \mathrm{pM}$ of each primer, $0.20 \mathrm{mM}$ dNTPs, $2.5 \mathrm{mM} \mathrm{MgCl}_{2}$, and $0.5 \mathrm{U}$ Taq DNA polymerase (TaKaRa, Dalian, China). The PCR protocol was as follows: $95^{\circ} \mathrm{C}$ for $5 \mathrm{~min} ; 35$ cycles of denaturing at $94^{\circ} \mathrm{C}$ for $30 \mathrm{~s}$, annealing at $60^{\circ} \mathrm{C}$ for $30 \mathrm{~s}$, and extension at $72^{\circ} \mathrm{C}$ for $30 \mathrm{~s}$; and a final extension at $72^{\circ} \mathrm{C}$ for $10 \mathrm{~min}$. The products for sequencing were first electrophoresed on $1.5 \%$ agarose gels, purified by Gel Extraction Kit (Omega, USA), and sequenced in both directions in an ABI PRIZM 377 DNA sequencer (ABI, USA). The sequence maps were analyzed by the SeqMan software. Through the DNA sequencing, 4 novel mutations (g.95925G $>$ A, g.95973G $>$ C, g.95992A $>$ G, and g.96058T $>$ C) were found. Furthermore, exon 1, exon 2, and exon 4 were carefully analyzed, and no variations were found.

\section{Genotyping of PRKAG2 alleles by PCR-RFLP and time-of-flight (TOF) technology}

PCR-RFLP was used to identify the g.95992A $>$ G mutation. A new primer pair (S: 5'-CGTGTTCCCGTTCTCCTAC-3'; A: 5'-CTACAGCCACCTGCCAGC-3') was designed to obtain 251-bp products from all cattle. The cycling protocol was $95^{\circ} \mathrm{C}$ for $5 \mathrm{~min} ; 35$ cycles of denaturing at $94^{\circ} \mathrm{C}$ for $30 \mathrm{~s}, 61.3^{\circ} \mathrm{C}$ annealing for $30 \mathrm{~s}$ and extension at $72^{\circ} \mathrm{C}$ for $30 \mathrm{~s}$; and a final extension at $72^{\circ} \mathrm{C}$ for $10 \mathrm{~min}$. Aliquots of $10 \mu \mathrm{L}$ of the PCR products were digested with $5 \mathrm{U} \mathrm{MspI}$ (TaKaRa) following the supplier manual. The digested products were detected by electrophoresis on a $2.5 \%$ agarose gel stained with ethidium bromide. To verify the results of the PCR-RFLP technique, the products with different electrophoresis patterns were sequenced.

As for the mutations g. $95925 \mathrm{G}>$ A, g. $95973 \mathrm{G}>$ C, and g. $96058 \mathrm{~T}>\mathrm{C}$, the products from the DNA samples were all sequenced to distinguish the genotypes of the 3 mutations by TOF mass spectrometry, which was completed at Sangon Biotech (Shanghai, China). 


\section{Statistical analysis}

Trait means were calculated by a generalized linear model. Genotypic and allelic frequencies, gene homozygosity, gene heterozygosity, Hardy-Weinberg equilibrium, effective allele numbers, and polymorphism information content (PIC) were statistically analyzed according to previous approaches (Nei and Roychoudhury, 1974; Nei and Li, 1979). The association between SNP marker genotypes of the PRKAG2 gene and BMTs and MQTs (BL, WH, HH, RL, HW, CD, HG, PBW, BT, LMA, and IFC) was analyzed by the SPSS software (version 17.0) according to the following statistical linear model:

$$
Y_{i j}=\mu+G_{i}+S_{j}+A_{l}+\varepsilon_{i j l}
$$

where $Y_{i j l}$ is the observation of the BMTs and ultrasound measurement traits, $\mu$ is the mean value for each trait, $G_{i}$ is the genotype effect, $S_{j}$ is the fixed effect of sex, $A_{l}$ is the fixed effect of age, and $\varepsilon_{i j l}$ is the random error.

\section{RESULTS}

\section{SNP identification and the $P R K A G 2$ genotypes}

The novel SNPs identified in this study were synonymous mutations g.95925G $>$ A (Figure 1a) and g.95973G $>$ C (Figure 1b) and the missense mutation g.95992A $>$ G (Figure 1c), resulting in a Ser to Gly substitution (75th amino acid), in exon 3 and a g.96058T $>\mathrm{C}$ mutation (Figure 1d) in intron 3. By TOF technology, all three 96058T $>\mathrm{C}$ genotypes were identified: TT, TC, and CC; only 2 g.95925G $>$ A genotypes were identified: GG and GA. The 3 g.95973G $>$ C genotypes (GG, GC, and CC) were also identified. For the g.95992A $>$ G polymorphism with 3 genotypes (AA, AG, and GG), the products digested with MspI showed 3 fragments $(251,154$, and $97 \mathrm{bp}$ ) for genotype $\mathrm{AG}, 1$ fragment (251 bp) for genotype AA, and 2 fragments (154 and $97 \mathrm{bp}$ ) for genotype GG (Figure 2).

\section{Genetic polymorphism of the Qinchuan cattle PRKAG2 gene and $\chi^{2}$ test}

For the mutations g.95925G $>$ A, g.95973G $>$ C, g.95992A $>$ G, and g.96058T $>$ C, the genotype and allele frequencies were analyzed, and the results are shown in Table 1 . The allele frequencies of g. $95925 \mathrm{G}>\mathrm{A}$ were $0.9542(\mathrm{G}) / 0.0458(\mathrm{~A})$, those of $\mathrm{g} .95973 \mathrm{G}>\mathrm{C}$ were $0.7439(\mathrm{G}) / 0.2561(\mathrm{C})$, those of g. $95992 \mathrm{~A}>\mathrm{G}$ were $0.7050(\mathrm{~A}) / 0.2950(\mathrm{G})$, and those of g.96058T $>$ C were $0.7301(\mathrm{~T}) / 0.2699(\mathrm{C})$. The $\chi^{2}$ test indicated that the genotype distributions of the 4 mutations were all in good accordance with Hardy-Weinberg equilibrium $\left(\chi^{2}\right.$ $<0.052$ ). The genetic indexes of each locus including homozygosity, heterozygosity, effective number of alleles, and PIC were calculated (Table 2). The PIC value of the mutations g.95925G $>$ A, g. $95973 \mathrm{G}>$ C, g.95992A $>$ G, and g.96058T $>$ C were $0.0837,0.3084,0.3294$, and 0.3164, respectively. According to the classification of PIC (high polymorphism if the PIC value is greater than 0.5 , medium polymorphism if the PIC value is between 0.25 and 0.5 , and low polymorphism if the PIC value is less than 0.25), the experimental Qinchuan cattle were in the medium polymorphism level at g.95973G $>$ C, g.95992A $>\mathrm{G}$, and g.96058T $>\mathrm{C}$; at g. $95925 \mathrm{G}>$ A, the population studied was in the low polymorphism level. 
$\mathbf{a}$

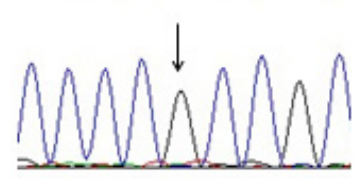

b

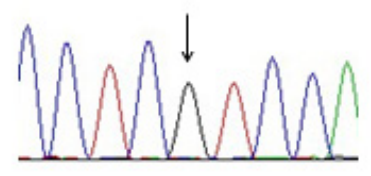

C

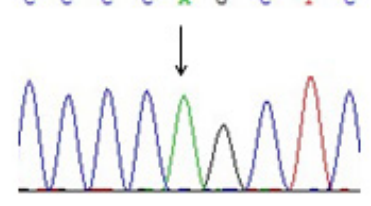

C $C$ C $C$ C A

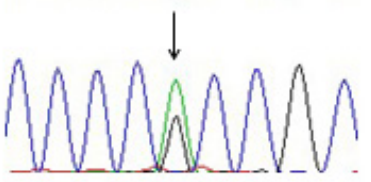

C C I C C I C C A
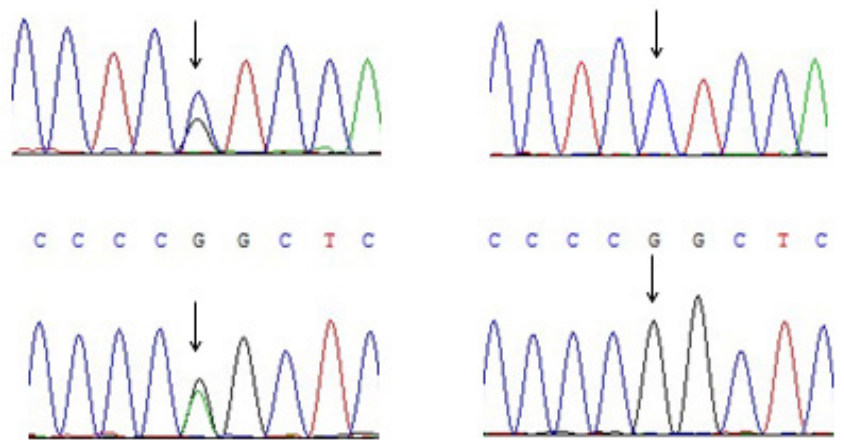

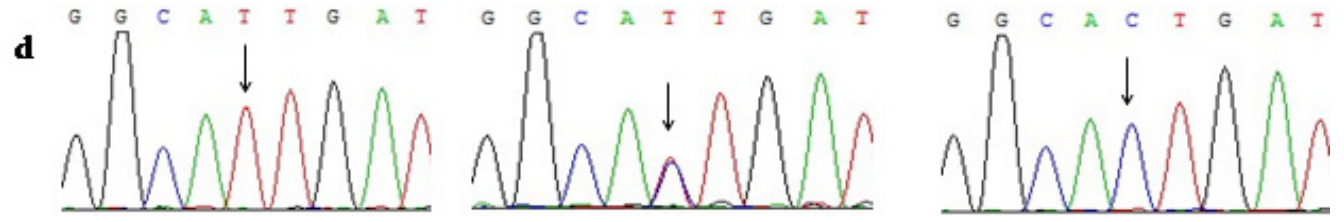

Figure 1. Sequencing map of the bovine $P R K A G 2$ gene. Single nucleotide polymorphisms are indicated using arrows. a. g. $95925 \mathrm{G}>$ A, b. g. $95973 \mathrm{G}>$ C, c. g. $95992 \mathrm{~A}>\mathrm{G}$, and d. g. $96058 \mathrm{~T}>\mathrm{C}$.

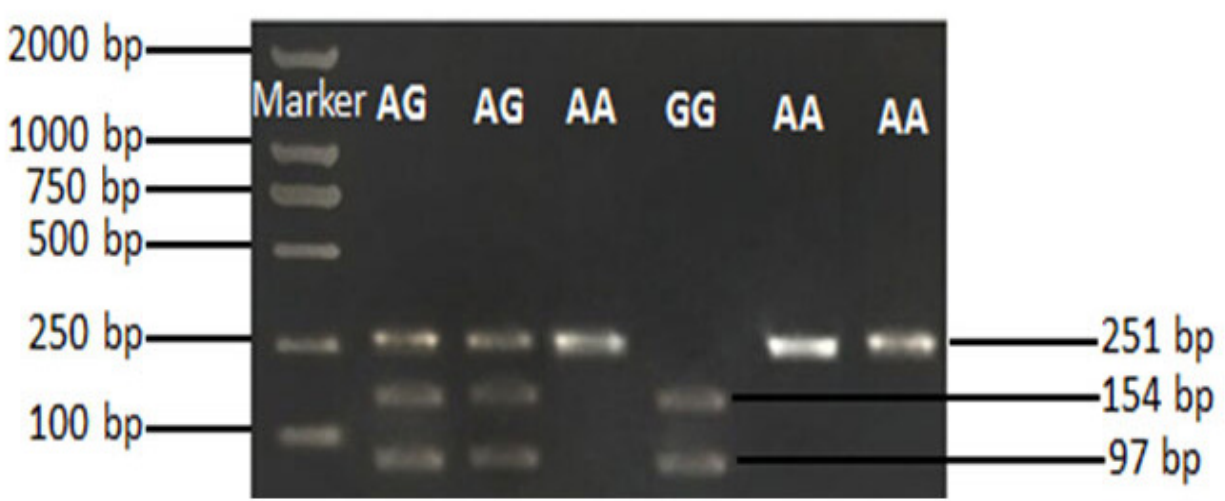

Figure 2. Restriction fragment length polymorphism electrophoresis pattern of the g.95992A $>$ G mutation in exon 3 of the Qinchuan cattle PRKAG2 gene. Marker: DL2000 (TaKaRa, Dalian, China). 
Table 1. Genotypic and allelic frequencies of PRKAG2 gene single nucleotide polymorphisms (SNPs) in the Qinchuan cattle population.

\begin{tabular}{|c|c|c|c|c|c|c|c|}
\hline \multirow{2}{*}{$\frac{\text { SNP }}{\text { g.95925G/A }}$} & \multicolumn{3}{|c|}{ Genotypic frequencies (number) } & \multirow{2}{*}{$\begin{array}{c}\text { Total } \\
578\end{array}$} & \multicolumn{2}{|c|}{ Allelic frequencies } & \multirow{2}{*}{$\frac{\chi^{2} \text { (HWE) }}{1.3345}$} \\
\hline & $\begin{array}{c}\mathrm{GG} \\
0.9083 \\
(526)\end{array}$ & $\begin{array}{c}\text { GA } \\
0.0917 \\
(51)\end{array}$ & $\begin{array}{c}\text { AA } \\
0 \\
(0)\end{array}$ & & $\begin{array}{c}\mathrm{G} \\
0.9542\end{array}$ & $\begin{array}{c}\mathrm{A} \\
0.0458\end{array}$ & \\
\hline g. $95973 \mathrm{G} / \mathrm{C}$ & $\begin{array}{c}\text { GG } \\
0.5727 \\
(320)\end{array}$ & $\begin{array}{c}\mathrm{GC} \\
0.3426 \\
(220)\end{array}$ & $\begin{array}{c}\text { CC } \\
0.0848 \\
(38)\end{array}$ & 578 & $\begin{array}{c}\mathrm{G} \\
0.7439\end{array}$ & $\begin{array}{c}\mathrm{C} \\
0.2561\end{array}$ & 5.8785 \\
\hline g. $95992 \mathrm{~A} / \mathrm{G}$ & $\begin{array}{c}\text { AA } \\
0.5156 \\
(287)\end{array}$ & $\begin{array}{c}\text { AG } \\
0.3789 \\
(240)\end{array}$ & $\begin{array}{c}\text { GG } \\
0.1055 \\
(50)\end{array}$ & 578 & $\begin{array}{c}\mathrm{A} \\
0.7050\end{array}$ & $\begin{array}{c}\mathrm{G} \\
0.2950\end{array}$ & 4.5845 \\
\hline g.96058T/C & $\begin{array}{c}\text { TT } \\
0.5415 \\
(308)\end{array}$ & $\begin{array}{c}\text { CT } \\
0.3772 \\
(228)\end{array}$ & $\begin{array}{c}\text { CC } \\
0.0813 \\
(42)\end{array}$ & 578 & $\begin{array}{c}\mathrm{T} \\
0.7301\end{array}$ & $\begin{array}{c}C \\
0.2699\end{array}$ & 1.0681 \\
\hline
\end{tabular}

$\mathrm{HWE}=$ Hardy-Weinberg equilibrium; $\chi 0.05^{2}=5.991, \chi 0.01^{2}=9.21$.

Table 2. Genetic indexes of PRKAG2 gene single nucleotide polymorphisms (SNPs) in the Qinchuan cattle population.

\begin{tabular}{lcccc}
\hline SNP & Gene homozygosity & Gene heterozygosity & Effective allele number & Polymorphic information content \\
\hline g.95925G/A & 0.9125 & 0.0875 & 1.0959 & 0.0837 \\
g.95973G/C & 0.6190 & 0.3810 & 1.6155 & 0.3084 \\
g.95992A/G & 0.5841 & 0.4159 & 1.7121 & 0.3294 \\
g.96058T/C & 0.6059 & 0.3941 & 1.6504 & 0.3164 \\
\hline
\end{tabular}

PIC $>0.5$ means high polymorphism; $0.25<$ PIC $<0.5$ means moderate polymorphism; PIC $<0.25$ means low polymorphism.

\section{Effects of the polymorphism locus on BMTs}

The association between $P R K A G 2$ variants and 8 BMTs was analyzed, and the results are shown in Table 3. For the g.95925G $>$ A mutation, no difference was found between the 2 genotypes (GG and GA) for the 8 BMTs studied $(P>0.05)$. At the g.95973G $>$ C locus, the mean value of BMTs of animals with genotype GG was significantly different from that with genotype $\mathrm{CC}$ for parameters $\mathrm{HH}$ and $\mathrm{CD}(\mathrm{P}<0.05)$; meanwhile, differences in RL and HW were observed between genotypes GG and GC with RL and HW. HH was different between genotypes $\mathrm{GC}$ and $\mathrm{CC}(\mathrm{P}<0.05)$. No difference was observed between genotypes for BL, $\mathrm{WH}, \mathrm{HG}$, and PBW $(\mathrm{P}>0.05)$. For g.95992A $>\mathrm{G}$, there was a significant difference in $\mathrm{WH}$ and $\mathrm{HW}$ between genotypes AA and GG, and there was also a significant difference in WH and $\mathrm{CD}$ between genotypes AG and $\mathrm{GG}(\mathrm{P}<0.05)$. Individuals with genotype AA had higher $\mathrm{HH}$ and $\mathrm{CD}$ than individuals with genotype $\mathrm{GG}(\mathrm{P}<0.01)$. Individuals with genotype $\mathrm{AG}$ also had higher HH than individuals with genotype GG $(\mathrm{P}<0.01)$. No difference was observed between genotypes AA, AG, and GG for BL, RL, HG, and PBW $(\mathrm{P}>0.05)$. At the g.96058T $>C$ locus, there was a significant difference between genotypes TT and $\mathrm{CC}$ and also between TC and $\mathrm{CC}$ for $\mathrm{WH}$ and $\mathrm{CD}(\mathrm{P}<0.05)$. A very significant difference was observed between genotypes TT and $\mathrm{CC}$ for HH $(\mathrm{P}<0.01)$; individuals with the TC genotype also had a significantly higher $\mathrm{HH}$ than individuals with the $\mathrm{CC}$ genotype $(\mathrm{P}<0.01)$. No difference was observed between any genotype for $\mathrm{BL}, \mathrm{RL}, \mathrm{HW}, \mathrm{HG}$, and $\mathrm{PBW}(\mathrm{P}>0.05)$. These results suggested that g. $95973 \mathrm{G}>\mathrm{C}$, g.95992A $>\mathrm{G}$, and g.96058T $>\mathrm{C}$ could be used as valuable markers to select excellent Qinchuan cattle with desired BMTs. 


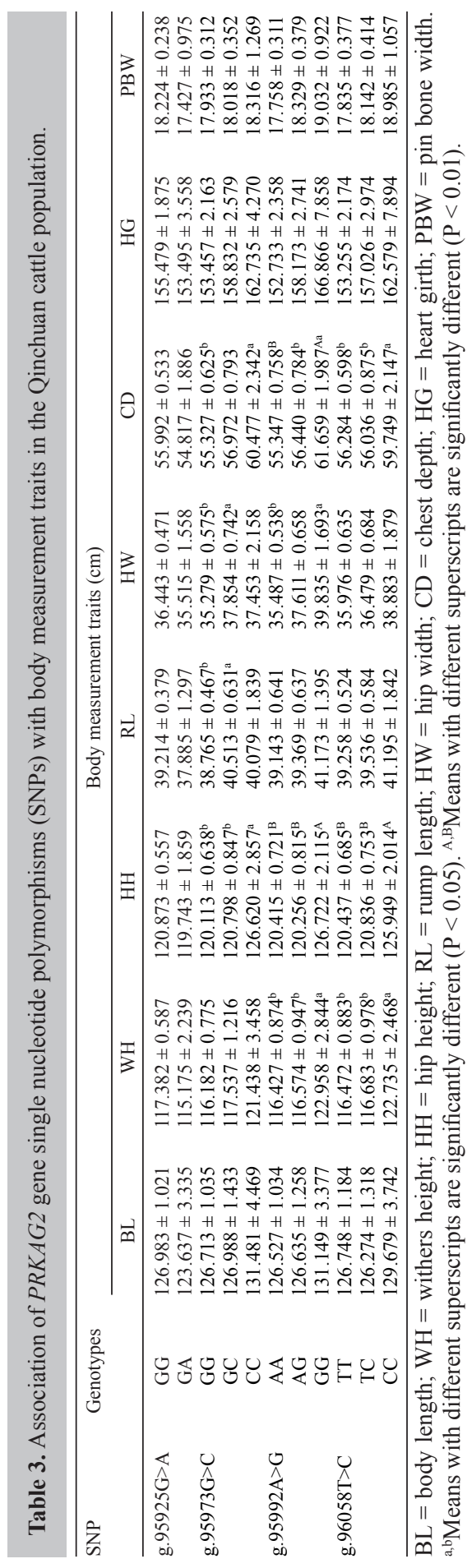




\section{Effects of polymorphisms on MQTs}

The associations between the 4 mutations and the 3 MQTs were analyzed, and the results are shown in Table 4. g. $95925 \mathrm{G}>\mathrm{A}$ had no significant effects on the 3 MQTs: BT, LMA, and IFC ( $\mathrm{P}>0.05)$. For g.95973G $>C$, the mean value of MQTs of individuals with genotype GG was very significantly higher than that of genotype GC for BT $(\mathrm{P}<0.01)$; LMA was significantly different between genotypes $\mathrm{GG}$ and $\mathrm{GC}(\mathrm{P}<0.05)$. At the g.95992A $>\mathrm{G}$ locus, there was a significant difference between genotypes $\mathrm{AA}$ and $\mathrm{AG}$ for $\mathrm{BT}$ and $\mathrm{LMA}(\mathrm{P}<0.05)$. For the g.96058T $>$ C mutation, a difference was only found between genotypes TT and TC for LMA (P $<0.05)$. For the 4 mutations, there was no difference between any genotype for IFC $(\mathrm{P}>0.05)$.

\begin{tabular}{|c|c|c|c|c|}
\hline \multirow[t]{2}{*}{ SNP } & \multirow[t]{2}{*}{ Genotypes } & \multicolumn{3}{|c|}{ Meat quality traits } \\
\hline & & BT (cm) & $\operatorname{LMA}\left(\mathrm{cm}^{2}\right)$ & IFC (\%) \\
\hline \multicolumn{5}{|c|}{ g. $95925 \mathrm{G}>\mathrm{A}$} \\
\hline & GG & $0.847 \pm 0.023$ & $47.874 \pm 1.477$ & $7.585 \pm 0.131$ \\
\hline & GA & $0.797 \pm 0.078$ & $43.538 \pm 4.968$ & $7.046 \pm 0.355$ \\
\hline \multicolumn{5}{|c|}{ g. $95973 \mathrm{G}>C$} \\
\hline & GG & $0.764 \pm 0.027^{\mathrm{B}}$ & $44.827 \pm 1.473^{b}$ & $7.483 \pm 0.137$ \\
\hline & $\mathrm{GC}$ & $0.938 \pm 0.036^{\mathrm{A}}$ & $50.018 \pm 2.287^{\mathrm{a}}$ & $7.579 \pm 0.147$ \\
\hline & $\mathrm{CC}$ & $0.836 \pm 0.131$ & $46.573 \pm 5.625$ & $7.405 \pm 0.544$ \\
\hline \multicolumn{5}{|c|}{ g. $95992 \mathrm{~A}>\mathrm{G}$} \\
\hline & AA & $0.793 \pm 0.029^{\mathrm{b}}$ & $45.487 \pm 1.858^{\mathrm{b}}$ & $7.385 \pm 0.121$ \\
\hline & $\mathrm{AG}$ & $0.907 \pm 0.033^{\mathrm{a}}$ & $50.794 \pm 2.173^{\mathrm{a}}$ & $7.636 \pm 0.143$ \\
\hline & GG & $0.845 \pm 0.079$ & $48.752 \pm 3.798$ & $7.697 \pm 0.349$ \\
\hline \multicolumn{5}{|c|}{ g. $96058 \mathrm{~T}>\mathrm{C}$} \\
\hline & TT & $0.817 \pm 0.025$ & $45.795 \pm 1.864^{b}$ & $7.517 \pm 0.114$ \\
\hline & TC & $0.884 \pm 0.035$ & $51.335 \pm 1.989^{\mathrm{a}}$ & $7.603 \pm 0.146$ \\
\hline & $\mathrm{CC}$ & $0.849 \pm 0.089$ & $47.887 \pm 4.753$ & $7.627 \pm 0.375$ \\
\hline
\end{tabular}

$\mathrm{BT}=$ backfat thickness; LMA $=$ loin muscle area; $\mathrm{IFC}=$ intramuscular fat content. ${ }^{\mathrm{a}, \mathrm{b}}$ Means with different superscripts are significantly different $(\mathrm{P}<0.05) .{ }^{\mathrm{A}, \mathrm{B}}$ Means with different superscripts are significantly different $(\mathrm{P}<0.01)$.

\section{DISCUSSION}

AMPK, a heterotrimer composed of $\alpha-, \beta$-, and $\gamma$-subunits, is a serine/threonine kinase; it works in the regulation of the glucose metabolic pathway in muscle (Gollob et al., 2002). The $\alpha$-subunit has effects on catalytic activity, whereas the $\gamma$-subunit is involved in regulating enzyme activation. PRKAG2, which encodes the $\gamma 2$ regulatory subunit of AMPK, is highly expressed in skeletal and cardiac muscle (Cheung et al., 2000). An essential role of AMPK is to function as a metabolic sensor in muscle, responding to cellular energy demands by depleting ATP stores (Hardie and Hawley, 2001; Winder, 2001). This function of AMPK suggested that PRKAG2 might be associated with maintaining an adequate ATP resource (Blair et al., 2001).

PRKAG2 plays a role in regulating key metabolic pathways in muscle, particularly glucose metabolism (Gollob et al., 2002). Therefore, we considered it as a candidate gene to explore its effects on animal growth. Identifying quantitative trait loci will facilitate the Chinese indigenous cattle breeding program, and molecular genetic information can also bring about significant positive developments for animals (Adoligbe et al., 2012). The candidate gene approach is a very effective method to analyze the association between gene polymorphisms and 
valuable economical traits in farm animals (Rothschild and Soller, 1997). Through the candidate gene approach, studies have been performed on animal reproduction (Chu et al., 2010), growth (Li et al., 2010), and MQTs (Jiao et al., 2010), which will provide more valuable data for further research. To facilitate the Chinese indigenous cattle-breeding program, further molecular genetic information on quantitative trait loci should be collected (Adoligbe et al., 2012).

PRKAG2, which is related to conduction system disease and cardiac hypertrophy (Gollob et al., 2002), is expressed at a high level in skeletal and cardiac muscle. Studies have demonstrated that PRKAG2 is associated with regulating key metabolic pathways in muscle, particularly in glucose metabolism (Gollob et al., 2002). These findings suggest that PRKAG2 may have effects on BMTs and MQTs in animals.

In this study, sequence analysis of PRKAG2 revealed 4 novel SNPs: 2 synonymous mutations, g.95925G $>$ A and g.95973G $>$ C, in exon 3; 1 missense mutation, g.95992A $>\mathrm{G}$, in exon 3 leading to the Ser to Gly change of the 75th amino acid; and 1 g.96058T $>\mathrm{C}$ mutation in intron 3. g.95973G $>$ C, g.95992A $>$ G, and g.96058T $>$ C showed 3 genotypes, whereas g. $95925 \mathrm{G}>\mathrm{A}$ showed 2 genotypes. The associations of $P R K A G 2$ polymorphisms with 8 BMTs (BL, WH, HH, RL, HW, CD, HG, and PBW) were analyzed using blood samples from 578 Qinchuan cattle. The possible relationships between the PRKAG2 polymorphisms and the 3 MQTs (BT, LMA, and IFC) were also evaluated. The results of the association analysis show that g. $95925 \mathrm{G}>\mathrm{A}$ has no significant effects on the BMTs and MQTs studied. g. $95973 \mathrm{G}>\mathrm{C}$ is associated with $\mathrm{HH}, \mathrm{RL}, \mathrm{HW}, \mathrm{CD}, \mathrm{HG}, \mathrm{BT}$, and LMA. CC seems to be the beneficial genotype for BMTs; however, for MQTs, the GC genotype is better. G.95992A $>\mathrm{G}$ is associated with $\mathrm{WH}, \mathrm{HH}, \mathrm{HW}, \mathrm{CD}, \mathrm{BT}$, and LMA. The GG genotype is better for BMTs; AG seems to be the beneficial genotype for MQTs. g.96058T $>\mathrm{C}$ is associated with $\mathrm{WH}, \mathrm{HH}$, $\mathrm{CD}$, and LMA. CC is the best genotype for BMTs, and TC is the best genotype for MQTs. The change of amino acid by the g.95992A $>$ G mutation may have effects on the function of the protein produced by the PRKAG2 gene, which may play a key role in glucose metabolism through AMPK. Studies suggested that introns and their removal by the spliceosome might have effects on gene expression at many different levels, including polyadenylation, transcription, translational efficiency, mRNA export, and the rate of mRNA decay (Nott et al., 2002). The absence of genotype AA at the g. $95925 \mathrm{G}>\mathrm{A}$ locus can be explained in 2 ways: this genotype does not exist at all, or it is due to the artificial selection. According to the results of this study, it is suggested that the PRKAG2 gene may have potential effects on BMTs and MQTs in the Qinchuan cattle population.

\section{CONCLUSIONS}

In this study, 4 novel SNPs of the PRKAG2 gene were revealed. g.95925G $>$ A, g. $95973 \mathrm{G}>\mathrm{C}$, and g.95992A $>\mathrm{G}$ were located in exon 3. g.96058T $>\mathrm{C}$ was located in intron 3. Association analysis results showed that g. $95925 \mathrm{G}>\mathrm{A}$ did not influence the traits that were studied, while the other 3 SNPs had significant effects on some of the BMTs and MQTs in the Qinchuan cattle population. Therefore, the PRKAG2 gene could be considered for markerassisted selection to improve growth and MQTs of Qinchuan cattle.

\section{ACKNOWLEDGMENTS}

We thank all the research assistants and laboratory technicians who contributed to 
this study. We extend special thanks to Professor Zan for his assistance. Research supported by the National 'Twelfth Five-Year' "863" Plan (\#2013AA102505), the National 'Twelfth Five-Year' "863" Plan (\#2011AA100307-02), the National Natural Science Foundation of China (\#31272411), the National Major Project of 'Twelfth Five-Year' Transgenic Breeding (\#2013ZX08007-002), and the Project of Constructing National Modern Agricultural and Industrial Technology System (\#CARS-38).

\section{REFERENCES}

Adoligbe C, Zan L, Farougou S, Wang H, et al. (2012). Bovine GDF10 gene polymorphism analysis and its association with body measurement traits in Chinese indigenous cattle. Mol. Biol. Rep. 39: 4067-4075.

Arad M, Benson DW, Perez-Atayde AR, McKenna WJ, et al. (2002). Constitutively active AMP kinase mutations cause glycogen storage disease mimicking hypertrophic cardiomyopathy. J. Clin. Invest. 109: 357-362.

Arad M, Moskowitz IP, Patel VV, Ahmad F, et al. (2003). Transgenic mice overexpressing mutant PRKAG2 define the cause of Wolff-Parkinson-White syndrome in glycogen storage cardiomyopathy. Circulation 107: 2850-2856.

Blair E, Redwood C, Ashrafian H, Oliveira M, et al. (2001). Mutations in the gamma(2) subunit of AMP-activated protein kinase cause familial hypertrophic cardiomyopathy: evidence for the central role of energy compromise in disease pathogenesis. Hum. Mol. Genet. 10: 1215-1220.

Brethour JR (1994). Estimating marbling score in live cattle from ultrasound images using pattern recognition and neural network procedures. J. Anim. Sci. 72: 1425-1432.

Cheung PC, Salt IP, Davies SP, Hardie DG, et al. (2000). Characterization of AMP-activated protein kinase gammasubunit isoforms and their role in AMP binding. Biochem. J. 346: 659-669.

Chu MX, Zhao XH, Zhang YJ, Jin M, et al. (2010). Polymorphisms of BMPR-IB gene and their relationship with litter size in goats. Mol. Biol. Rep. 37: 4033-4039.

Davies JK, Wells DJ, Liu K, Whitrow HR, et al. (2006). Characterization of the role of gamma2 R531G mutation in AMPactivated protein kinase in cardiac hypertrophy and Wolff-Parkinson-White syndrome. Am. J. Physiol. Heart Circ. Physiol. 290: H1942-H1951.

Gilbert RP, Bailey DR and Shannon NH (1993). Linear body measurements of cattle before and after 20 years of selection for postweaning gain when fed two different diets. J. Anim. Sci. 71: 1712-1720.

Gollob MH, Green MS, Tang AS, Gollob T, et al. (2001). Identification of a gene responsible for familial Wolff-ParkinsonWhite syndrome. N. Engl. J. Med. 344: 1823-1831.

Gollob MH, Green MS, Tang AS and Roberts R (2002). PRKAG2 cardiac syndrome: familial ventricular preexcitation, conduction system disease, and cardiac hypertrophy. Curr. Opin. Cardiol. 17: 229-234.

Hamlin KE, Green RD, Cundiff LV, Wheeler TL, et al. (1995). Real-time ultrasonic measurement of fat thickness and longissimus muscle area: II. Relationship between real-time ultrasound measures and carcass retail yield. J. Anim. Sci. 73: 1725-1734.

Hardie DG and Hawley SA (2001). AMP-activated protein kinase: the energy charge hypothesis revisited. Bioessays 23: 1112-1119.

Jiao Y, Zan LS, Liu YF, Wang HB, et al. (2010). A novel polymorphism of the MYPN gene and its association with meat quality traits in Bos taurus. Genet. Mol. Res. 9: 1751-1758.

Li F, Chen H, Lei CZ, Ren G, et al. (2010). Novel SNPs of the bovine GAD1/gad67 gene and their association with growth traits in three native Chinese cattle breeds. Mol. Biol. Rep. 37: 501-505.

Müllenbach R, Lagoda PJ and Welter C (1989). An efficient salt-chloroform extraction of DNA from blood and tissues. Trends Genet. 5: 391.

Nei M and Roychoudhury AK (1974). Sampling variances of heterozygosity and genetic distance. Genetics 76: 379-390.

Nei M and Li WH (1979). Mathematical model for studying genetic variation in terms of restriction endonucleases. Proc. Natl. Acad. Sci. U. S. A. 76: 5269-5273.

Nkrumah JD, Li C and Basarab JB (2003). Association of a single nucleotide polymorphism in the bovine leptin gene with feed intake, feed efficiency, growth, feeding behavior, carcass quality and body composition. Can. J. Anim. Sci. 84: 211-219.

Nott A, Meislin SH and Moore MJ (2002). A quantitative analysis of intron effects on mammalian gene expression. RNA 9: 607-617.

Ofir M, Arad M, Porat E, Freimark D, et al. (2008). Increased glycogen stores due to gamma-AMPK overexpression protects against ischemia and reperfusion damage. Biochem. Pharmacol. 75: 1482-1491.

Oliveira SM, Zhang YH, Solis RS, Isackson H, et al. (2012). AMP-activated protein kinase phosphorylates cardiac troponin I and alters contractility of murine ventricular myocytes. Circ. Res. 110: 1192-1201. 
Rothschild MF and Soller M (1997). Candidate gene analysis to detect genes controlling traits of economic importance in domestic livestock. Probe 8: 13-22.

Sidhu JS, Rajawat YS, Rami TG, Gollob MH, et al. (2005). Transgenic mouse model of ventricular preexcitation and atrioventricular reentrant tachycardia induced by an AMP-activated protein kinase loss-of-function mutation responsible for Wolff-Parkinson-White syndrome. Circulation 111: 21-29.

Weedon MN, Lettre G, Freathy RM, Lindgren CM, et al. (2007). A common variant of HMGA2 is associated with adult and childhood height in the general population. Nat. Genet. 39: 1245-1250.

Winder WW (2001). Energy-sensing and signaling by AMP-activated protein kinase in skeletal muscle. J. Appl. Physiol. 91: 1017-1028 